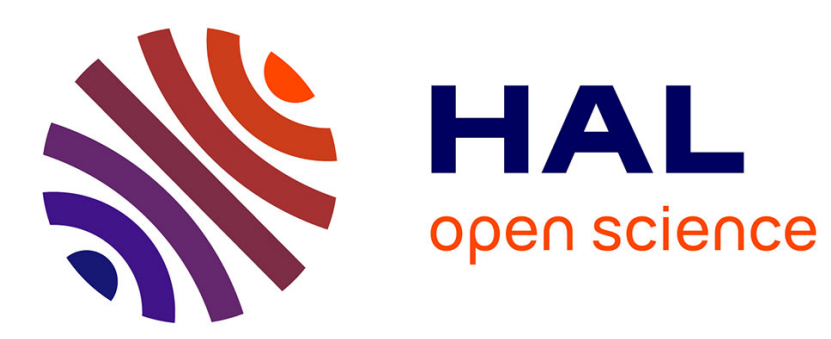

\title{
Ferroelectricity of Europium Manganese Oxide EuMn2O5 with Helimagnetic Ordering
}

\author{
H. Nakamura, M. Ishikawa, K. Kohn
}

\section{To cite this version:}

H. Nakamura, M. Ishikawa, K. Kohn. Ferroelectricity of Europium Manganese Oxide EuMn2O5 with Helimagnetic Ordering. Journal de Physique IV Proceedings, 1997, 07 (C1), pp.C1-365-C1-366. 10.1051/jp4:19971149 . jpa-00254793

\section{HAL Id: jpa-00254793 https://hal.science/jpa-00254793}

Submitted on 1 Jan 1997

HAL is a multi-disciplinary open access archive for the deposit and dissemination of scientific research documents, whether they are published or not. The documents may come from teaching and research institutions in France or abroad, or from public or private research centers.
L'archive ouverte pluridisciplinaire HAL, est destinée au dépôt et à la diffusion de documents scientifiques de niveau recherche, publiés ou non, émanant des établissements d'enseignement et de recherche français ou étrangers, des laboratoires publics ou privés. 


\title{
Ferroelectricity of Europium Manganese Oxide $\operatorname{EuMn}_{2} \mathrm{O}_{5}$ with Helimagnetic Ordering
}

\author{
H. Nakamura, M. Ishikawa, K. Kohn and M. Ishikawa* \\ Department of Physics, Waseda University; Shinjuku-ku, Tokyo 169, Japan \\ * Institute for Solid State Physics, University of Tokyo, Minato-ku, Tokyo 106, Japan
}

\begin{abstract}
From the measurements of pyroelectricity, dielectric constant, magnetic susceptibility and specific heat, we conclude that $\mathrm{EuMn}_{2} \mathrm{O}_{5}$ is ferroelectric below the Curie temperature $T_{\mathrm{C}}$ of $38.6 \mathrm{~K}$. This temperature coincides with the Néel temperatire of the helimagnetic ordering of $\mathrm{Mn}^{3+}$ and $\mathrm{Mn}^{4+}$ moments within the accuracy of the measurements. The spontaneous polarization is along the $b$-direction.
\end{abstract}

\section{INTRODUCTION}

Rare earth manganites $\mathrm{RMn}_{2} \mathrm{O}_{5}(\mathrm{R}=\mathrm{Nd}-\mathrm{Lu}, \mathrm{Y}$ or $\mathrm{Bi})$ have a helical magnetic ordering of $\mathrm{Mn}^{3+}$ and $\mathrm{Mn}^{4+}$ spins below $T_{\mathrm{N}}$ of about $40 \mathrm{~K}$.[1] A strong interrelation is expected between the electric and magnetic properties in these oxides because of the presence of a $\mathrm{Mn}^{3+}$ and, in some cases, a rare earth ion which have a tendency to a distorted coordination. In fact, most $\mathrm{RMn}_{2} \mathrm{O}_{5}$ show a large magnetoelectric effect at low temperatures.[2] Particularly, we proposed the possibility of a simultaneous ferroelectric transition at $T_{\mathrm{N}}$ in $\mathrm{EuMn}_{2} \mathrm{O}_{5}$, based on the dielectric, magnetic and magnetoelectric measurements.[3] However, direct demonstration of ferroelectricity has been lacking. The purpose of this study is to make this point clear. We made pyroelectric measurements to demonstrate the presence of spontaneous polarization and determine its temperature dependence. In addition, we made simultaneous measurements of dielectric constant and magnetic susceptibility, and specific heat measurements in order to know whether both ferroelectric and magnetic transitions take place at the same temperature. The results is that EuMn $\mathrm{O}_{5}$ is ferroelectric below $40 \mathrm{~K}$, which coincides with magnetic transition temperature within $\pm 0.3 \mathrm{~K}$.

\section{EXPERIMENTAL METHODS}

We used two kinds of samples. The sample for the measurement of pyroelectricity is a single crystal of the same batch of the one used in a previous study.[3] The others were polycrystals prepared by an ordinary ceramic method. The composition determined by ICP analysis was $\mathrm{Eu}_{1.00} \mathrm{Mn}_{2.02} \mathrm{O}_{5 \pm \alpha}$. No line of phases other than EuMn $\mathrm{O}_{5}$ could be observed in the powder Xray pattern, though the small remanent magnetization indicated the presence of the precipitate of $\mathrm{Mn}_{3} \mathrm{O}_{4}$ or $\mathrm{EuMnO}_{3}$. $\mathrm{The}$ polycrystalline samples were used in the measurements of the dielectric constant, magnetic susceptibility and specific heat. The pyroelectric current was detected along the $b$-direction of the single crystal sample with an electrometer. Preceding to each measurement run, the samples were poled by cooling down from 77 to $4.2 \mathrm{~K}$ in electric field of 5 or $-3 \mathrm{kV} / \mathrm{cm}$ along the $b-$ direction. The spontaneous polarization $P_{\mathrm{S}}$ was derived by integrating the recorded current. The details were described elsewhere.[4] The magnetic susceptibility was measured by a vibration sample magnetometer with a specially designed sample rod. The dielectric constant was measured simultaneously by an impedance analyzer connected to the electrodes on the sample through coaxial cables set in the sample rod. Specific heat measurements were carried out with a heat-pulse and a continuous heating method in an adiabatic calorimeter installed at the Institute for Solid State Physics, University of Tokyo. The relative calibration of the temperature scales of two kinds of measurements were not carried out yet.

\section{RESULTS AND DISCUSSION}

Figure 1 shows the temperature dependence of the spontaneous polarization $P_{\mathrm{S}}$ along the $b$-direction. With increasing temperature, $P_{\mathrm{S}}$ decreases monotonously and vanishes at about $39 \mathrm{~K}$. Two curves correspond to opposite directions of electric field $E_{\text {cool }}$ applied during cooling the sample down to $4.2 \mathrm{~K}$. The sign of $P_{\mathrm{S}}$ was switched by reversing $E_{\text {cool }}$. Figure 2 and Figure 3 depict the temperature dependencies of the magnetic susceptibility and dielectric constant measured simultaneously. An arrow indicates the temperature $T_{\mathrm{N}}$ of the magnetic transition estimated in the following way; we reconstructed the 
femperature dependence of powder susceptibility $\chi_{\mathrm{p}}$ from our previous data of the susceptibilities $\chi_{a}, \chi_{b}$ and $\chi_{c}$ along fhe three principal axes of a single crystal (shown in the inset of Fig. 2) [3], and then we determined the point corresponding to $T_{\mathrm{N}}$ by comparing the recorded and the reconsfructed temperature dependence of $\chi_{\mathrm{p}}$ on an assumption that the cusp in $\chi_{a}$ corresponds with $T_{\mathrm{N}}$. The accuracy of the determination was within $0.3 \mathrm{~K}$. Figure 4 shows the temperature dependence of specific heat. Only a single peak is present around $40 \mathrm{~K}$ see the insel for more detail), showing again that both ferroelectric and magnetic transitions occur in a narrow temperature range.

The above results indicate that EuMn $\mathrm{O}_{5}$ las spontaneous polarization, which can be switched by external electric field, below $T_{\mathrm{c}}$ of $40 \mathrm{~K}$. In other words it is ferroelectric below this temperature. The ferroelectric Curic temperature $T_{\mathrm{c}}$ and the Nécl tcmperature $T_{\mathrm{N}}$ are coincident within $0.3 \mathrm{~K}$. If the formation of magnetic ordering is accompanied with ionic displacensent

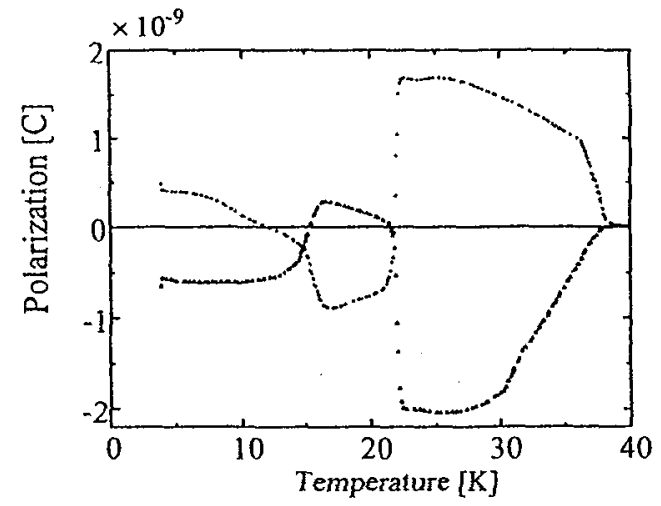

Figure 1: Temperature dependence of spontancous polarization of Jix $\mathrm{Mn}_{2} \mathrm{O}_{5}$ along the b-dircction. Two curves correspond to opposite direction of electric field applied during cooling.

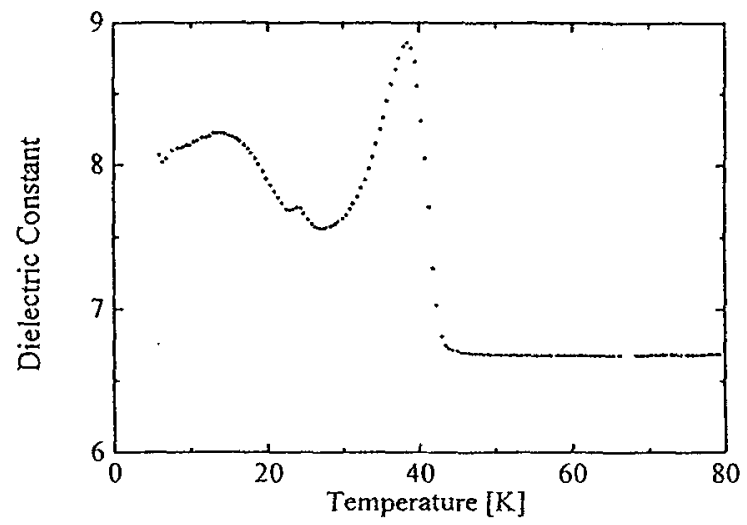

lïgure 3: Temperature depencience of diclectric constant of powder sample of $\mathrm{FuMn}_{2} \mathrm{O}_{5}$. The data of Figures 2 and 3 were recorded in the same experimental nun.

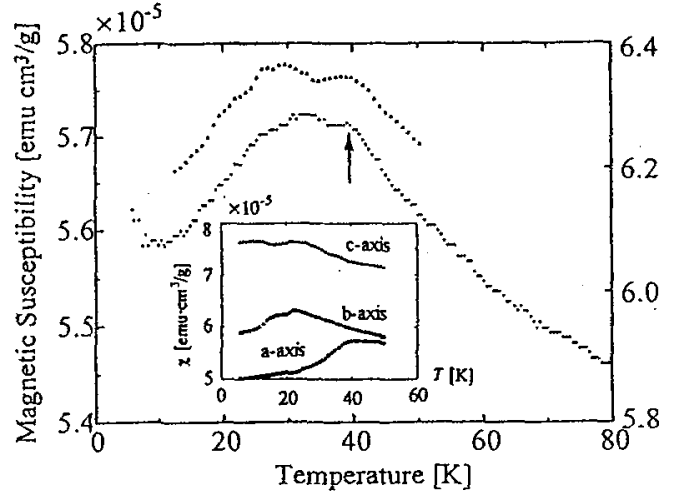

Figure 2: Temperature dependence of the observed (triangles) and the estimated (circies) powder magnetic susceptibility of $\mathrm{EuMn}_{2} \mathrm{O}_{5}$. The insel shows the temperature dependence of principal susceptibilitics used in the estimation.

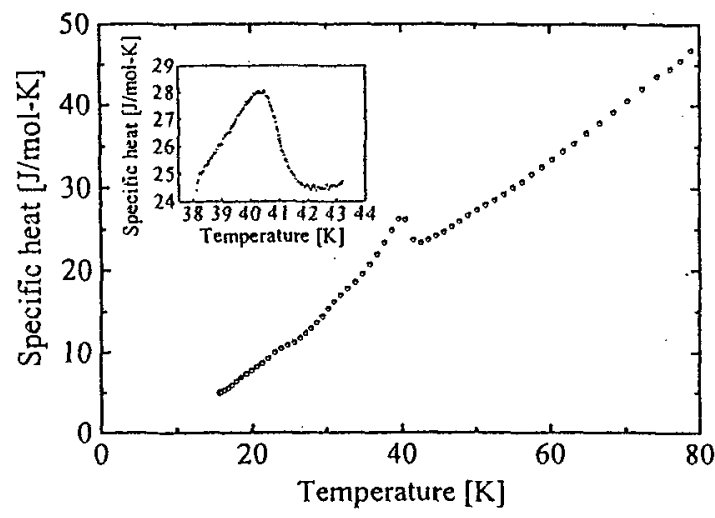

Iigure 4: Temperature dependence of specific heat of $1 \mathrm{suMn}_{2} \mathrm{O}_{5}$. The insel shows the data measured between 38 and $43 \mathrm{~K}$ with a continuous heating method.

Jeading to ferroclectricity, it is a new type of transition. The mechanism is not yet clear. However, it is probable that the magnetic long range ordering brings the change in the state of a $\mathrm{Mn}^{3+}$ ion with $3 \mathrm{~d}^{4}$ configuration and then the relative displacement of it relative to surrounding oxygen ions. It is a subject of our further study.

\section{References}

[1]Gardner P., Wilkinson C., Forsyth J.B. and Wanklyn B.M.R., J. P'hys.C: Solid State Phys. 21(1988) 5653-5661, and the papers cited therein.

12|Kolnn K., Ferroelectrics 162(1994) 1-9, and the papers cited therein.

[3]Doi T. and Kohn K., Phase Transitions 38(1992) 273-284.

[4]Inomata A. and Kolln K., J. Phys. C Condensed Matter 8(1996) 2673-2678. 